\title{
Interorganizational Information Systems: A Study of Practice
}

\author{
Bernardo Agrelos $^{1}$, João Vitor Ferreira ${ }^{1}$, Bruna Diirr ${ }^{1}$ \\ ${ }^{1}$ Universidade Federal do Estado do Rio de Janeiro (UNIRIO) - Rio de Janeiro - Brasil \\ bernardo.agrelos@edu.unirio.br, \{joao.ferreira, bruna.diirr\}@uniriotec.br
}

\begin{abstract}
Interorganizational relationships are initiatives between organizations that aim to facilitate resource sharing and information exchange. In this context, information systems are developed to support the involved organizations, often encompassing several smaller systems. However, little is known about interorganizational information systems (IOIS), especially regarding their state of practice. This paper investigates the use of IOISs in real scenarios. For this, we performed a non-systematic search of IOISs examples and identified repositories on GitHub about these systems. Hence, it was possible to map a set of sources and requirements that help understand how IOISs work and why they are adopted.
\end{abstract}

\section{Introduction}

Aiming at dealing with strategic tensions, remaining competitive, or expanding their reach, organizations establish relationships with other organizations and engage in interorganizational relationships: a mutual involvement where there are possibilities for exchanging skills, sharing resources, and proposing solutions that go beyond the existing elements in their current limits and capabilities [Drews and Schimer 2014, Mueller et al. 2013, Ranaei et al. 2010, Van Fenema et al., 2014].

An important tool in these relationships is the Interorganizational Information Systems (IOIS). These systems are, by definition, shared by two or more organizations, thus supporting the performed activities, information processing, and communication between stakeholders, which implies a level of cooperation that goes beyond the relationships and interactions commonly observed between organizations [Barrett and Konsynski 1982, Scott and Mula 2009].

However, although some academic works aim to understand interorganizational relationships and IOISs better [Diirr e Cappelli 2018, Diirr e Santos 2019], there is still an investigation gap regarding real cases. These works offer only a theoretical perspective on the topic, thus limiting the investigation of practical aspects.

This paper investigates the use of IOIS in real scenarios. Considering the confidentiality often involved in such systems, public sources were used in the two steps to understand the state of practice of interorganizational relationships and IOIS. The first step involved a non-systematic search of interorganizational relationships examples, where 9 interorganizational relationships were found and classified. The second step comprised a search for IOIS repositories on GitHub, where 22 repositories were found and analyzed to understand such systems' characteristics.

The paper is organized as follows: Section 2 introduces the theoretical foundation used in the project. Section 3 explains the adopted methodology. Section 4 discusses the obtained results. Finally, Section 5 concludes the paper. 


\section{Theoretical foundation}

Interorganizational relationships comprise any process between organizations that, based on exchanges and/or collaboration, seek mutual benefit and solutions to problems to achieve a common goal [Drews and Schimer 2014, Mueller et al. 2013, Ranaei et al. 2010, Van Fenema et al., 2014]. These relationships vary in structure/type, being a less structured relationship, where interaction takes place informally, or a more structured relationship, which varies from a weak collaboration, when one organization has more power than the others (i.e., mergers, outsourcing, acquisition, etc.) to strong collaboration, when organizations have power equality (i.e., consortium, alliance, cooperatives, etc.) [Ranaei et al. 2010]. Also, they collaborate throughout the phases of the interorganizational relationship lifecycle: creation, operation, evaluation, evolution, and dissolution [Afsarmanesh e Camarinha-Matos, 2009, Van Fenema et al., 2014].

Organizations engaged in interorganizational relationships can use IOISs to collaborate for achieving mutual goals. IOISs, as well as other information systems, can collect, store, transform, and share data, being shared by two or more organizations and supporting the interorganizational relationship lifecycle phases [Barrett and Konsynski 1982, Scott and Mula 2009]. However, the characteristics of interorganizational relationships or the lack of deeper knowledge about them affect the adopted systems, thus causing the non-specification of a complete IOIS and the difficulty of identifying and managing people involved in IOIS development [Boonstra e de Vries 2008].

However, despite growing investment in interorganizational relationships and IOISs, there is still a gap regarding real cases. Existing research focuses on a theoretical perspective on these topics, often limiting the investigation and discussion of practical aspects [Diirr e Santos 2019].

\section{Methodology}

This project investigates the use of IOIS in real scenarios. First, a non-systematic search was performed on websites and online research platforms for identifying interorganizational relationship examples. 9 reports of interorganizational relationships were found and analyzed. This allowed identifying some information about these relationships, such as involved organizations, type of relationship, collaboration strength, IOISs adoption, and the goal that justifies the interorganizational relationship.

After that, the GitHub platform was used for mining repositories related to IOIS to identify and understand IOISs main characteristics. Hence, the following search strings were used: "interorganizational", "interorganizational system", "crossorganizational", and "cross-organizational system". 152 repositories were identified and, due to the GitHub search tool limitations, individually analyzed. The analysis comprised the selection of repositories through minimum requirements, thus excluding duplicate repositories, empty repositories, or repositories that only have text files without any code. After that, the remaining 87 repositories were analyzed, from which 22 repositories were selected and classified as IOIS. Repositories analysis provided a better understanding of IOISs requirements and functionalities, also allowing to retrieve information regarding their scope, phase of the interorganizational relationship lifecycle in which the IOIS is used, interorganizational relationship structure, economic sector in which the IOIS is applied, if requirements are described in README file, requirements detailing level, and who is responsible for requirements eliciting (a person or a group). 


\section{Results}

The results of non-systematic search and repositories mining were organized and analyzed $^{1}$. The 9 reports from the non-systematic search allowed the identification of some interorganizational relationship characteristics. 7 reports detail strong relationships (6 partnerships and a joint selling), and 2 detail weak relationships (a contract and a relationship between Brazilian government agencies). All relationships are structured, and among large organizations from different areas, such as Apple, McDonald's, Microsoft, Samsung, IBM, Google, Ericsson, and Verizon. These multinationals engage in relationships, but they also created relationships with smaller companies or the government to achieve a common goal.

Repository mapping resulted in 22 repositories holding IOIS. The README file provided useful information about the repository, explaining the system's purpose and detailing the system's requirements. Those projects might be time-consuming, but only 4 repositories were developed by a group, while 9 were developed by a single person and 9 were not specified. Analysis shows that 16 repositories do not provide enough details for requirements eliciting, but the description of their purpose or some functionality was sufficient to classify them as IOIS. The 22 systems were also classified according to interorganizational relationship lifecycle support: 6 IOISs assist creation, providing functionalities to facilitate partners prospecting and contact; 22 IOISs support operation, as they have tools for resources sharing or allow actions to achieve common goals; and 6 IOIS help evaluation, as they provide information about the partnership for goals/performance analysis. No repositories support the evolution and dissolution of interorganizational relationships, but 4 IOISs support 3 interorganizational relationships lifecycle phases. Analysis also allowed identifying the sector in which IOISs are used ( 5 related to the third sector; 3 to the second sector; 14 do not have a specific sector) and these IOISs structure (13 operates interdependencies between organizations (networked); 5 IOISs involves IT resources sharing (pooled information); 1 IOIS sequence interdependencies between organizations (supply chain))

Regarding the IOISs requirements, some were identified and highlighted as they resemble requirements identified by Diirr e Santos (2019). They relate to partner management, such as partner profile and search tool; strategy definition, like obligations; communication and documents exchange, like shared databases; design of tasks/protocols/decisions, such as the possibility to add roles, rules, and policies to a collaborative event; creation and management of multiple collaborative spaces, such as a tool to create multiples events so organizations can collaborate.

\section{Conclusion}

Interorganizational relationships allow organizations interested in achieving common goals to share resources and exchange information. However, little is known about the IOISs that support this collaborative work, especially regarding the state of practice.

This paper investigated real cases of interorganizational relationships and IOISs. The 9 reports and 22 repositories offered inputs on such systems and their uses, thus making it possible to map a set of sources and requirements that allows understanding how IOISs work and why they are adopted. It is observed that such systems can be

\footnotetext{
${ }^{1}$ http://bit.ly/WICSI-SBSI2021
} 
private or public and with different functions, such as storage, sharing, and even data simulation. They can also share information via the web or more directly, as a data messenger between parties. However, there was a lack of detail on how such systems work, often informing only their scope and the lifecycle phase they support. Also, many IOISs are business-oriented and rarely open to the public, which has made the analysis limited to open source and non-profit systems.

As future work, requirements will serve as input for developing the framework for interorganizational relationship management and supporting IOIS. Besides that, we aim to conduct experiments for applying this framework and IOIS in real scenarios to evaluate their impact and gather inputs that help their improvement.

\section{Acknowledgments}

This research was supported by UNIRIO [Edital PPInst-UNIRIO 2020].

\section{References}

Afsarmanesh, H.; Camarinha-Matos, L. (2009) "On the classification and management of virtual organization breeding environments", International Journal of Information Technology and Management, v. 8, n.3, pp.234-259.

Barret, S.; Konsynski, B. (1982) "Inter-organizational information sharing systems", MIS Quarterly, v. 6, pp. 93-105.

Boonstra, A.; de Vries, J. (2008) "Managing stakeholders around inter-organizational systems: A diagnostic approach", The Journal of Strategic Information Systems, v. 17, n.3, pp. 190-201.

Diirr, B.; Cappelli, C. (2018) "A systematic literature review to understand crossorganizational relationship management and collaboration", In Hawaii International Conference on System Sciences, pp. 145-154, Hawaii.

Diirr, B.; Santos, G. (2019) "A Systematic Literature Mapping on Interorganizational Information Systems", In: Americas Conference on Information Systems, Cancun.

Drews, P.; Schirmer, I. (2014) "From Enterprise Architecture to Business Ecosystem Architecture", In International Enterprise Distributed Object Computing Conference, pp. 13-22, Ulm.

Mueller, T.; Schuldt, D.; Sewald, B.; Morisse, M.; Petrikina, J. (2013) “Towards Interorganizational Enterprise Architecture Management", In Americas Conference on Information Systems, Chicago.

Ranaei, H.; Zareei, A.; Alikhani, F. (2010) "Inter-organizational Relationship Management: A Theoretical Model", International Bulletin of Business Administration, v. 9, pp. 20-30.

Scott, A.; Mula, J. (2009) "Contextual Factors associated with Information Systems in a Virtual Supply Chain", In International Conference on Cooperation and Promotion of Information Resources in Science and Technology, pp. 348-354, Beijing.

Van Fenema, P.; Keers, B.; Zijm, H. (2014) "Interorganizational Shared Services: Creating Value across Organizational Boundaries”, Shared Services as a New Organizational Form, v. 13, pp. 175-217. 